\title{
Differences in Elderly and Non-Elderly Outpatient Subjective Evaluation of "Easy-to-Eat Meals" after Dental Treatment
}

\author{
Mai Ohkubo ${ }^{1)}$, Takayuki Ueda ${ }^{2)}$, Keina Miura ${ }^{1)}$, Hiroki Sugito ${ }^{3,4)}$, \\ Mikiko Kawaguchi $^{{ }^{5}}$, Keisuke Ono ${ }^{6)}$, Fumi Seshima ${ }^{7)}$, Toshiyuki Morioka ${ }^{8)}$, \\ Saki Uchiyama ${ }^{9)}$, Mitsutaka Yoshida ${ }^{10)}$ and Yasutomo Yajima ${ }^{10)}$
}

${ }^{1)}$ Department of Oral Health and Clinical Science, Division of Dysphagia Rehabilitation, Tokyo Dental College, 2-9-18 Kanda-Misakicho, Chiyoda-ku, Tokyo 101-0061, Japan

2) Department of Removable Prosthodontics and Gerodontology, Tokyo Dental College, 2-9-18 Kanda-Misakicho, Chiyoda-ku, Tokyo 101-0061, Japan

${ }^{3)}$ Department of Operative Dentistry, Cariology and Pulp Biology, Tokyo Dental College, 2-9-18 Kanda-Misakicho, Chiyoda-ku, Tokyo 101-0061, Japan

${ }^{4)}$ Department of Dental Hygiene, Tokyo Dental Junior College, 2-9-18 Kanda-Misakicho, Chiyoda-ku, Tokyo 101-0061, Japan

${ }^{5}$ Department of Food Science, Faculty of Home Economics, Otsuma Women's University, 12 Sanban-cho, Chiyoda-ku, Tokyo 102-8357, Japan

${ }^{6)}$ Department of Oral and Maxillofacial Surgery, Tokyo Dental College, 2-9-18 Kanda-Misakicho, Chiyoda-ku, Tokyo 101-0061, Japan

${ }^{7)}$ Department of Periodontology, Tokyo Dental College, 2-9-18 Kanda-Misakicho, Chiyoda-ku, Tokyo 101-0061, Japan

${ }^{8)}$ Department of Removable Partial Prosthodontics, Tokyo Dental College, 2-9-18 Kanda-Misakicho, Chiyoda-ku, Tokyo 101-0061, Japan

${ }^{9}$ Suidobashi Hospital, Tokyo Dental College, 2-9-18 Kanda-Misakicho, Chiyoda-ku, Tokyo 101-0061, Japan

${ }^{10)}$ Department of Oral Implantology, Tokyo Dental College, 2-9-18 Kanda-Misakicho, Chiyoda-ku, Tokyo 101-0061, Japan

Received 1 February, 2019/Accepted for Publication 5 November, 2019 Published Online in J-STAGE 14 August, 2020

\begin{abstract}
Dental treatment improves the experience of eating by healing illnesses in the oral cavity or through the installation of special devices. However, mastication can often prove difficult for short periods of time after dental treatment, potentially limiting the types of food that can be consumed. Therefore, we proposed a highly nutritious meal strategy for dental outpatients (hereafter, "easy-to-eat meals"). We previously reported patients' subjective assessment of these easy-to-eat meals as determined through a questionnaire survey. The purpose of the present study was to investigate how differences in age affected such assessments. The study participants comprised patients scheduled to undergo den-
\end{abstract}


tal treatment. They were divided into 2 groups: one of patients aged above and one of those aged below 70 years. All were required to consume provided easy-to-eat meals at the dental hospital directly after treatment and then answer a questionnaire. The questionnaire included items on patient satisfaction with the meals, taste, portion size, convenience, reduction in discomfort, and whether they would consume them again. The format of the questionnaire was a visual analog scale (VAS), ranging from 0 (negative) to 10 (positive). Portion size was to be rated on a scale from 0 ("Not enough") to 10 ("Too much"), with 5 being "Just right". Correlations between the questionnaire items were investigated to determine how they influenced each other. The VAS average for "Reduction in discomfort" was $8.45 \pm 1.39$ in the non-elderly group and $6.07 \pm 2.92$ in the elderly group, and the difference was significant $(p=0.02)$; the VAS average for "Taste" was $6.49 \pm 2.32$ in the non-elderly group and $4.91 \pm 0.98$ in the elderly group, and the difference was significant $(p=0.04)$. The results of this study suggest that providing such meal plans as nutritional guidance after dental treatment can influence quality of life in elderly patients.

Key words: Nutrition — Quality of life — Food — Survey

\section{Introduction}

Eating is a fundamental and indispensable activity for sustaining life ${ }^{15)}$. However, it is not merely a means of obtaining the nutrients required for survival; it is also a pleasurable activity, and one that is strongly related to quality of life (QoL). Abocclusion and masticatory dysfunction-in other words, not having teeth-have a significant effect on nutrition, often leading to higher cholesterol and lower fiber intake ${ }^{8}$. Dental treatment improves the experience of eating by healing illnesses in the oral cavity or through the installation of special devices ${ }^{9}$, and hence many studies have compared post-treatment QoL and activities of daily living ${ }^{3,4,12,16)}$. However, during and directly after treatment, pain and swelling can temporarily make it difficult to consume food. For example, chewing can become physically impossible after dental surgery, the mounting of new dentures, or when there is pain caused by the movement of teeth after orthodontic treatment. This can make mastication difficult for a period of time, potentially limiting the type of food that can be consumed. While this does not necessarily mean it is completely impossible to eat after dental treatment, the patient may not be able to consume their customary diet, or only being able to take liquids for several days in a clinical setting. Patients do usually recover soon afterward. This does not mean, however, that such discomfort due to the invasiveness of dental treatment may be ignored, so it is necessary to find some solution if QoL is not to be reduced. Moreover, a previous study in the Netherlands reported that malnutrition is prevalent in approximately $20 \%$ of geriatric outpatients, while more than half of such outpatients are at risk thereof ${ }^{18)}$. Therefore, we believe that it is urgent to respond to the needs of elderly people who are at risk of malnutrition after dental treatment. In an earlier study by this group, dental outpatients were given a standardized meal plan comprising highly nutritious ready-to-eat meals, gelatins, and drinks (hereafter, "easy-to-eat meals"). The patients were then required to subjectively assess these easy-to-eat meals through a questionnaire survey ${ }^{11}$. The purpose of the present study was to investigate how differences in age affected such assessment. 


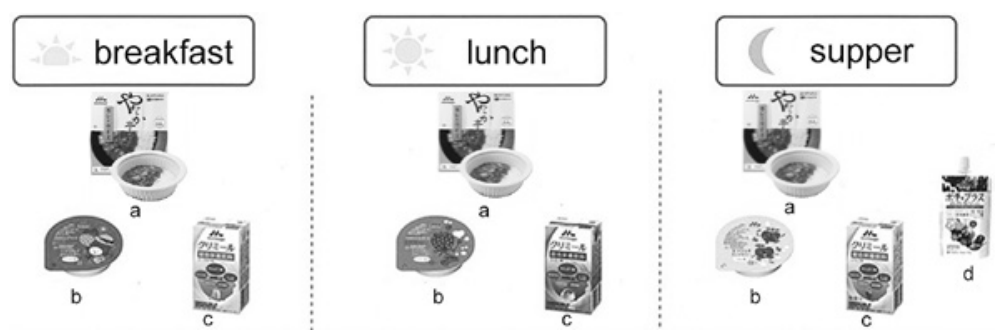

Fig. 1 Single set of easy-to-eat meals.

a: soft rice-based meals, b: nutritious gelatins, c: dense liquid food products, $d$ : hydrating gelatins

\section{Materials and Methods}

\section{Participants}

The study participants comprised patients attending the Suidobashi Hospital of Tokyo Dental College. The patients were divided into 2 groups: an elderly group, comprising patients aged $70 \mathrm{yr}$ or above; and a non-elderly group, comprising patients aged below $70 \mathrm{yr}$. In terms of damage to the oral cavity, selection was limited to patients who had undergone provisional restoration or had had dentures fitted, whose Eichner subgroup was A or $\mathrm{B} 1$, and who had retained molar occlusion. Examples of eligible treatments included mounting of dentures immediately after tooth extraction, molar periodontal surgery, full-arch or classical restoration, and implants in the molar area of the oral cavity. Dysphagia or difficulty swallowing, food allergies, dietary restrictions due to systemic disorders, or requirement of eating assistance meant exclusion from the study. The departments involved in providing treatment comprised prosthodontics, operative dentistry, oral surgery, oral implantology, and orthodontics. The protocol of this study was reviewed and approved by the Tokyo Dental College Ethics Committee (authorization no. 675). All participants provided written informed consent.

\section{Easy-to-eat meals}

Easy-to-eat meals were defined as a combination of store-bought highly nutritious soft rice-based meals (ready-to-eat meals), gela- tins, and drinks. A balanced amount of protein, zinc, iron, and fiber was taken into account. Foodstuffs employed mainly consisted of the following: Yawaraka-tei soft ricebased meals (200 g); Enjoy Capsule Jelly nutritious gelatins (70 g); Enjoy Creameal dense liquid food products $(125 \mathrm{ml})$; and Petit Plus Drinkable Jelly hydrating gelatins (100 g), all of which are manufactured by Clinico (Tokyo, Japan). A single set of easy-to-eat meals contained a combination of these food items considered sufficient for 4 days with 3 meals/ day (Fig. 1). Consumption of these meals was commenced from the day of treatment, while the patient was still experiencing pain or other discomfort. The Dietary Reference Intakes for Japanese ${ }^{7}$ was referred to in establishing the appropriate average daily nutritional content required for women aged $70 \mathrm{yr}$ or above. This guideline is primarily aimed at women, making it ideal for the purposes of the present study, as most of the participants were female. The details are given in Table 1 .

\section{Survey method}

All the participants were patients scheduled to undergo dental treatment. Consumption of the meals was commenced directly after treatment on-site at the Suidobashi Hospital of Tokyo Dental College. Subjective assessment of these easy-to-eat meals was achieved through a questionnaire survey. The survey period was from June 2016 to September 2017. Each participant was to consume at least a 1-day set of easy-to-eat meals. 
Table 1 Nutritional contents of easy-to-eat meals and dietary reference intakes for Japanese outpatients (women aged 70 years or above) (per day)

\begin{tabular}{|c|c|c|c|}
\hline & & $\begin{array}{c}\text { Easy-to-eat } \\
\text { meals }^{* 1}\end{array}$ & $\begin{array}{l}\text { Dietary Reference } \\
\text { Intakes for Japanese } \\
\text { (females } 70 \text { years } \\
\text { and above) }\end{array}$ \\
\hline Calories & (kcal) & $1,397.5$ & 1,750 \\
\hline Protein & (g) & 47.1 & 50 \\
\hline Fat & $(\mathrm{g})$ & 29.8 & $39-58$ \\
\hline Carbohydrates & $(\%)$ & 73 & $50-65$ \\
\hline Salt equivalent & (g) & 5.4 & Less than 7.0 \\
\hline Potassium & $(\mathrm{mg})$ & $1,227.5$ & 2,000 \\
\hline Calcium & $(\mathrm{mg})$ & $1,137.0$ & 650 \\
\hline Magnesium & $(\mathrm{mg})$ & 264.0 & 270 \\
\hline Phosphorus & $(\mathrm{mg})$ & 864.5 & 800 \\
\hline Iron & $(\mathrm{mg})$ & 30.0 & 6.0 \\
\hline Zinc & $(\mathrm{mg})$ & 36.3 & 7 \\
\hline Copper & $(\mathrm{mg})$ & 1.3 & 0.7 \\
\hline Dietary fiber & (g) & 22.2 & 17 \\
\hline Vitamin A & $(\mu \mathrm{g})$ & $1,015.0$ & 650 \\
\hline Vitamin D & $(\mu \mathrm{g})$ & 7.6 & 5.5 \\
\hline Vitamin E & $(\mathrm{mg})$ & 17.9 & 6.0 \\
\hline Vitamin B1 & $(\mathrm{mg})$ & 2.6 & 0.9 \\
\hline Vitamin B2 & $(\mathrm{mg})$ & 3.1 & 1.1 \\
\hline Niacin & $(\mathrm{mg})$ & 36.5 & 10 \\
\hline Vitamin B6 & $(\mathrm{mg})$ & 3.7 & 1.2 \\
\hline Vitamin B12 & $(\mathrm{mg})$ & 7.2 & 2.4 \\
\hline Folate & $(\mathrm{mg})$ & 630.0 & 240 \\
\hline Vitamin C & $(\mathrm{mg})$ & 656.0 & 100 \\
\hline
\end{tabular}

${ }^{* 1}$ The average daily intake content for four days with three meals

Items in the questionnaire addressed reduction in discomfort, satisfaction, taste, convenience, whether participants would consume these meals again, and portion size. The format of the questionnaire was a visual analog scale (VAS), with possible answers ranging from 0 (negative) to 10 (positive). For example, possible responses to "Did the meals reduce discomfort when eating after dental treatment?" (hereafter, "Reduction in discomfort") ranged from 0 ("Did not reduce discomfort at all") to 10 ("Reduced discomfort significantly"); those to "Were you satis- fied with the meals?" (hereafter, "Satisfied") ranged from 0 ("Not at all satisfied") to 10 ("Very satisfied"); those to "How did they taste?" (hereafter, "Taste") ranged from 0 ("Not at all tasty") to 10 ("Very tasty"); those to "Did you find the meals convenient, such as by not having to make them yourself?" (hereafter, "Convenience") ranged from 0 ("Not at all convenient") to 10 ("Very convenient"); those to "Would you like to use these meals again if you receive similar dental treatment in the future" (hereafter "Likelihood of reuse") ranged from 0 ("Would not use 
Table 2 Age and number of members in non-elderly and elderly groups

\begin{tabular}{lcc}
\hline \hline & Non-elderly group & Elderly group \\
\hline $\mathrm{n}$ & 34 & 7 \\
Age (years) mean $\pm \mathrm{SD}$ & $46.1 \pm 17.1$ & $80.9 \pm 5.6$ \\
the youngest age-the oldest age & $14-69$ & $72-88$ \\
Male : female (n) & $11: 23$ & $1: 6$ \\
& & \\
Clinical Departments & & 5 \\
Prosthesis & 10 & 2 \\
Conservative Dentistry & 1 & 0 \\
Orthodontics & 6 & 0 \\
Implant Dentistry & 17 & \\
\hline
\end{tabular}

again") to 10 ("Would definitely use again"); and those to "How about the portion size?" ranged from 0 ("Not enough") to 10 ("Too much"), with 5 indicating "Just right".

The VAS for each questionnaire item was compared between a non-elderly and elderly group.

\section{Statistical analysis}

The Mann-Whitney $U$ test was used to compare the non-elderly and elderly groups. All data analyses were performed using SPSS, version 23 (IBM Corp., Armonk, NY, USA). A p-value of $<0.05$ was considered statistically significant.

\section{Results}

A total of 41 participants were enrolled during the experimental period. All participants were to consume 1 from a set of 3 easy-to-eat meals, while at other meal times, they were required to select 1 item from the remaining 2. A total of 34 participants were assigned to the non-elderly group (average age, $46.1 \pm 17.1 \mathrm{yr})$ and 7 to the elderly group (average age, $80.9 \pm 5.6 \mathrm{yr}$ ) (Table 2). The VAS average for "Reduction in discomfort" was $8.45 \pm 1.39$ in the non-elderly group and $6.07 \pm 2.92$ in the elderly group; a significant difference was found $(p=0.02)$. The VAS average score for "Satisfied" was $6.89 \pm 2.27$ in the non-elderly group and $6.10 \pm 1.90$ in the elderly group; here, the difference was not significant. The VAS average for "Taste" was $6.49 \pm 2.32$ in the non-elderly group and $4.91 \pm 0.98$ in the elderly group; a significant difference was found $(p=0.04)$. The VAS average score for "Convenience" was $8.93 \pm 1.62$ in the non-elderly group and $8.79 \pm 0.84$ in the elderly group; and the VAS average score for "Likelihood of reuse" was $6.21 \pm 2.90$ in the non-elderly group and $5.83 \pm 2.14$ in the elderly group. No significant difference was observed for these items. Moreover, the VAS average for "Portion size" was $4.01 \pm 1.72$ in the non-elderly group and $5.17 \pm 0.62$ in the elderly group. The former thus thought the portion size relatively small, whereas the latter felt it was just about right. A significant difference was observed here $(\mathrm{p}=0.04)($ Table 3$)$.

\section{Discussion}

From pain to having a lisp and difficulty masticating, the condition of the oral cavity is said to greatly influence QoL ${ }^{17)}$. Its health is also said to affect what we eat, our mental state, and our smile ${ }^{1}$. There is, therefore, a strong relationship between the condition of the oral cavity and QoL, and if the former is 
Table 3 Visual analog scale results for each questionnaire item in non-elderly and elderly groups

\begin{tabular}{|c|c|c|c|c|c|c|c|}
\hline \multirow[b]{2}{*}{$\begin{array}{l}\text { Reduction in } \\
\text { discomfort }\end{array}$} & \multirow[b]{2}{*}{$\begin{array}{l}\text { 0: Did not reduce } \\
\text { discomfort at all }\end{array}$} & \multirow[b]{2}{*}{$\begin{array}{l}\text { 10: Reduced } \\
\text { discomfort } \\
\text { significantly }\end{array}$} & \multicolumn{2}{|c|}{$\begin{array}{l}\begin{array}{c}\text { Non-elderly } \\
\text { group }\end{array} \\
\text { Visual Analog } \\
\text { Scale (SD) }\end{array}$} & \multicolumn{2}{|c|}{$\begin{array}{l}\text { Elderly group } \\
\text { Visual Analog } \\
\text { Scale (SD) }\end{array}$} & \multirow{2}{*}{$\begin{array}{r}\mathrm{p} \text { value } \\
0.02 *\end{array}$} \\
\hline & & & 8.45 & $(1.39)$ & 6.07 & $(2.92)$ & \\
\hline Satisfaction & $\begin{array}{l}0: \text { Not at all } \\
\text { satisfied }\end{array}$ & 10: Very satisfied & 6.89 & $(2.27)$ & 6.10 & $(1.90)$ & 0.27 \\
\hline Taste & $0:$ Not at all tasty & 10: Very tasty & 6.49 & $(2.32)$ & 4.91 & $(0.98)$ & $0.04^{*}$ \\
\hline Convenience & $\begin{array}{l}0: \text { Not at all } \\
\text { convenient }\end{array}$ & $\begin{array}{l}\text { 10: Very conven- } \\
\text { ient }\end{array}$ & 8.93 & (1.62) & 8.79 & $(0.84)$ & 0.25 \\
\hline $\begin{array}{l}\text { Likelihood of } \\
\text { reuse }\end{array}$ & $\begin{array}{l}0 \text { : Would not use } \\
\text { again }\end{array}$ & $\begin{array}{l}\text { 10: Would } \\
\text { definitely use } \\
\text { again }\end{array}$ & 6.21 & $(2.90)$ & 5.83 & $(2.14)$ & 0.60 \\
\hline Portion size & 0: Too little & 10: Too much & 4.01 & $(1.72)$ & 5.17 & $(0.62)$ & $0.04^{*}$ \\
\hline
\end{tabular}

$* \mathrm{p}<0.05$ : Mann-Whitney $U$ test

unhealthy, it can negatively affect diet. This is even more serious in the elderly, who have been shown to exhibit decreased appetite ${ }^{6)}$ and may thus miss out on important nutri$e^{2 n} s^{5}$. Malnourished older persons have an increased risk of sarcopenia due to reduced muscle protein synthesis ${ }^{2}$. However, it can be hard for patients to get enough protein when they have pain in the oral cavity, as proteinrich meats and fish require chewing. Moreover, malnourishment further causes protein degradation.

A number of studies have investigated patient satisfaction ${ }^{13)}$ and $\mathrm{QOL}^{10)}$ before and after dental treatment. However, to our knowledge, none have investigated patient QoL directly after the process of treatment. Factors that decrease post-treatment QoL include change in occlusion, as well as pain and swelling due to inflammation, which may limit the type of food that can be consumed. That is why we proposed standardized easy-toeat meals, focusing on post-treatment diet and QoL. This enabled us to understand the problems patients face in eating directly after dental treatment.

On dividing the participants into an elderly or non-elderly group, a significant difference was observed in the areas of "Reduction in discomfort" and "Taste". The elderly participants were not accustomed to vacuum-packed ready-to-eat meals, so it led to neither a reduction in discomfort nor ease of enjoyment. However, the non-elderly group was familiar with this type of meal and did not object to eating them, which was related to the reported reduction in discomfort and satisfaction with taste. Further research regarding how to pack and serve such meals may be necessary, as people can experience changes in sense of taste and smell as they age ${ }^{6)}$. In addition, because the meals look like ready-made goods, elderly people, who already exhibit a diminished interest in food $^{6)}$, may find it difficult to enjoy them. Reijnierse et al. reported an association between loss of appetite and being underweight, demonstrating that diagnostic measures of sarcopenia were strongest for both relative and absolute muscle mass ${ }^{14}$.

As providing standardized meals, as done in the present study, is only cost-effective in the short-term, it may be necessary to find other solutions, such as catering, nutritional guidance, or other methods of cooking, 
depending on the characteristics and preferences of the patients. However, in the present study, the easy-to-eat meals aspect demonstrated no significant difference with regard to "Convenience", with both groups giving it a high rating. This could be because such meals eliminate the need for the patient to go out for food or cook when pain and swelling would make it difficult to do so, regardless of age. Regardless of whether the meals are the same as the ones proposed by us, such nutritional guidance after treatment is necessary for elderly patients.

Among the limitations of this study were (a) the use of only one kind of easy-to-eat meals plan; (b) the difference in sex and small number of participants; and (c) the fact that, because the questionnaire only asked for broad assessments, it was not possible to investigate in detail which factors enhanced enjoyment of the meals or how exactly discomfort was reduced. Moreover, satisfaction with meals depends not only on age, but also on treatment content, and the number of times such easy-to-eat meals are consumed. Therefore, it is possible that there was considerable bias with respect to the taste of the food and other factors. Moreover, the influence of differences in dental treatment on the results cannot be denied. It may be possible to clarify this point, however, by analyzing the opinions of non-elderly and elderly people who have not undergone dental treatment as controls. That was another limitation of this study that may be addressed in further study.

Nevertheless, to our knowledge, this is the first study of its kind, and we believe that these results can serve as a reference in clinical practice and for research on nutritional guidance for outpatients receiving general dental treatment. Nutritional guidance by nutritionists is no longer commonly available in general dental clinics. Therefore, it may be necessary for the dentist to provide such nutritional advice at general dental clinics in the future, especially in the case of elderly patients. Such advice must include not only the nutrition that they need, but also how they can get it. To improve the QoL and prevent malnutrition in the elderly, such post-treatment guidance must become an indispensable part of dental treatment, along with a shift away from the idea that being temporarily unable to eat is a natural consequence of treatment.

Questionnaires were administered to patients who consumed easy-to-eat meals to determine their efficacy directly after dental treatment. Differences were observed between elderly and non-elderly patients regarding "Reduction in discomfort" and "Taste". Because such meals look like readymade goods, it may be difficult for elderly people to perceive them as reducing discomfort and being tasty. However, for the elderly, it may be necessary to provide nutritional advice at general dental clinics. This suggests that providing such meal plans as part of posttreatment nutritional guidance, with the goal of influencing QoL, may depend on the age of the patient. That is, it is necessary to investigate the appetites of elderly people.

\section{Acknowledgements}

We are sincerely grateful to Takako Murakoshi, a nationally certified dietician at Tokyo Dental College Suidobashi Hospital, for her advice on nutrition.

\section{Disclosure}

Companies and groups that represent a conflict of interest with this study and necessitate disclosure are shown below.

Clinico Co., Ltd. provided the foods used in this research for free at the authors' request. Clinico Co., Ltd. did not participate in the planning of this study. No consultation, speaking fees, contracted research, collaborative research funding, or scholarship contributions were received in association with this study. 


\section{References}

1) Adulyanon S, Vourapukjaru J, Sheiham A (1996) Oral impacts affecting daily performance in a low dental disease Thai population. Community Dent Oral Epidemiol 24: 385-389.

2) Boirie Y, Morio B, Caumon E, Cano NJ (2014) Nutrition and protein energy homeostasis in elderly. Mechanisms of Ageing and Development 136:76-84.

3) Boven GC, Raghoebar GM, Vissink A, Meijer $\mathrm{HJ}$ (2014) Improving masticatory performance, bite force, nutritional state and patient's satisfaction with implant overdentures: a systematic review of the literature. J Oral Rehabil 42:220-233.

4) Chaukar DA, Walvekar RR, Das AK, Deshpande MS, Pai PS, Chaturvedi P, Kakade A, D'Cruz AK (2009) Quality of life in head and neck cancer survivors: a cross-sectional survey. Am J Otolaryngol 30:176-180.

5) Drewnowski A, Shultz JM (2001) Impact of aging on eating behaviors, food choices, nutrition and health status. J Nutr Health Aging 5: 75-79.

6) Hetherington MM (1999) Taste and appetite regulation in the elderly. Proc Nutr Soc 57: 625-631.

7) Japanese Ministry of Health, Labour and Welfare. Overview of Dietary Reference Intakes for Japanese (2015) 8-40. Available from: https://www.mhlw.go.jp/file/06-Seisaku jouhou-10900000-Kenkoukyoku/Full_ DRIs2015.pdf

8) Joshipura KJ, Willett WC, Douglass CW (1996) The impact of edentulousness on food and nutrient intake. J Am Dent Assoc 127: 459-467.

9) Locker D, Allen F (2007) What do measures of oral health-related quality of life measure? Community Dent Oral Epidemiol 35: 401-411.

10) Naito M, Kato T, Fujii W, Ozeki M, Yokoyama M, Hamajima N, Saitoh E (2009) Effects of dental treatment on the quality of life and activities of daily living in institutionalized elderly in Japan. Arch Gerontol Geriatr 50: 65-68.
11) Ohkubo M, Ueda T, Miura K, Sugito H, Ono K, Seshima F, Morioka T, Uchiyma S, Yoshida M, Yajima Y (2019) "Easy-to-eat meals" for outpatients following dental treatment. Bull Tokyo Dent Coll 60:225-232.

12) Omeje KU, Adebola AR, Efunkoya AA, Osunde OD, Bamgbose BO, Akhiwu BI, Amole IO (2015) Prospective study of the quality of life after treatment of mandibular fractures. $\mathrm{Br} \mathrm{J}$ Oral Maxillofac Surg 53: 342-346.

13) Pan YH, Lin TM, Liang CH (2014) Comparison of patient's satisfaction with implant-supported mandibular overdentures and complete dentures. Biomed J 37:156-162.

14) Reijnierse EM, Trappenburg MC, Leter MJ, Blauw GJ, de van der Schueren MA, Meskers CG, Maier AB (2015) The association between parameters of malnutrition and diagnostic measures of sarcopenia in geriatric outpatients. PLoS One 10: e0135933.

15) Report of the Joint WHO/FAO Expert Consultation. Nutrition and the Prevention of Chronic Diseases, WHO Technical Report Series 916. Geneva, WHO Library Cataloguingin-Publication Data (2003) Available from: http://apps.who.int/iris/bitstream/handle/ 10665/42665/WHO_TRS_916.pdf

16) Singh KA, Brennan DS (2012) Chewing disability in older adults attributable to tooth loss and other oral conditions. Gerodontology 29: 106-110.

17) Slade GD, Spencer AJ (1994) Social impact of oral conditions among older adults. Aust Dent J 39:358-364.

18) van der Laan LN, de Ridder DT, Viergever MA, Smeets PA (2011) The first taste is always with the eyes: A meta-analysis on the neural correlates of processing visual food cues. Neuroimage 55:296-303.

\section{Correspondence:}

Dr. Mai Ohkubo

Department of Oral Health and Clinical Science, Division of Dysphagia Rehabilitation, Tokyo Dental College, 2-9-18 Kanda-Misakicho, Chiyoda-ku, Tokyo 101-0061, Japan E-mail: mokubo@tdc.ac.jp 